\title{
Dental enterprise is finalist in NHS Parliamentary Awards
}

Peninsula Dental Social Enterprise (PDSE) has been recognised as the South West Regional Winner in The Health Equalities Award category of the NHS Parliamentary Awards 2020 for its successful Community Clinic, which supports vulnerable patients who are experiencing homelessness in Plymouth.

For successfully winning the regional category, PDSE are now shortlisted for the national award which will be announced at a ceremony at the Palace of Westminster in July 2021.

The award, which can only be nominated through a Member of Parliament, recognises the work that the clinic, run by a small team of professionals from Peninsula Dental Social Enterprise and local agencies and associations, is providing a number of patients who are currently experiencing homelessness within the city with urgent and routine dental care.

Robert Witton, CEO of PDSE and Director of Social Engagement and Community-based Dentistry in the University of Plymouth's Peninsula Dental School says: 'On behalf of PDSE I would like to thank Luke Pollard

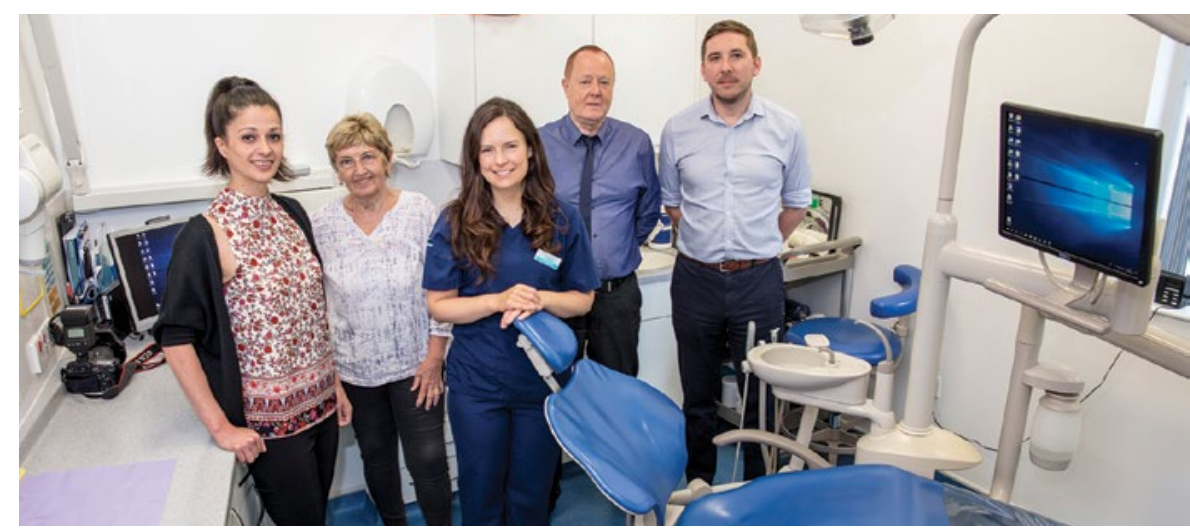

From left to right: Martha Paisi, Post Doctoral Researcher at the University of Plymouth, Lyndsey Withers long-standing volunteer with The Salvation Army, Christina Worle, Dentist at PDSE, Colin Massey, Head of Patient Administration at PDSE and Rob Witton, Chief Executive at PDSE and Director of Social Engagement and Community-Based Dentistry at University of Plymouth

MP for nominating us for this award. We are absolutely committed to addressing oral health inequalities in local communities and helping those who need it most through the Community Clinic. I am grateful to all of our partners for making this initiative so successful.

The clinic began in January 2018 by treating people experiencing homelessness, expanding within the last year to include individuals using drug and alcohol services, as well as vulnerable women who are at risk of having multiple children removed from their care.

PDSE currently provides this service as a pro bono contribution to the local community as part of its mission to ensure access to dental care for groups who may feel excluded from mainstream dentistry.

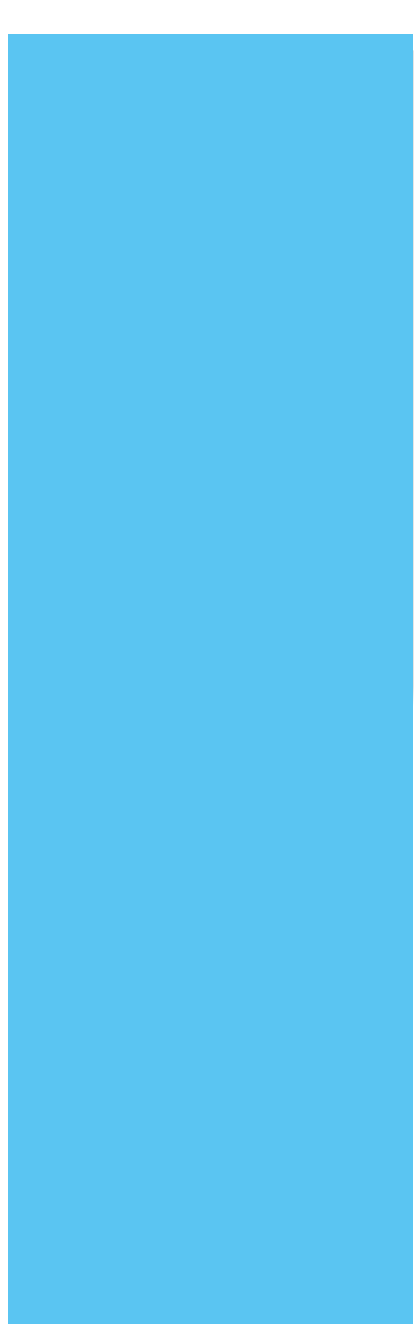

